\title{
A Decision Support Model about Medical Community Based on CBR Bing Jiang ${ }^{1, a}$, Cheng Liu ${ }^{1, b}$ \\ ${ }^{1}$ College of Business, Sichuan Agricultural University , Sichuan 611830,China;

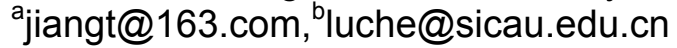

Keywords: model, Community, Medical health management, Decision support, Case base.

\begin{abstract}
The level of information management community health care in our country is not high , and the technology is very scarce. In this paper, we raise a decision support model about community medical, in the light of the degree of information is far from enough. The paper discussed how to design 、 build and retrieve, to the target community case library. In the end, the paper conduct a experiment simulation using statistical data of five community health examination for two consecutive years, and the experiment indicate that the result using the model to calculate is consistent with the actual. This model can provide recommendations for improvement for community health continuously, so it has certain application value.
\end{abstract}

\section{Introduction}

At this stage, the people status of sub health is generally existence in our country, it due to that the people have Weak consciousness about healthy diet and health, perhaps that is why the physical of people decline continuously. With the increasingly for the information level, the health examination and statistics will realize for community residents. The community residents are increasingly concerned about their own health, however, the degree of information and intelligence is low for community health management. The information construction of community health management have a long time in foreign country, there are already many intelligent information systems on medical health, which are used in the community, (Freddy,2012) develop the hypertension information management systems and it are used in the community, the hypertensive patients of community get the relevant adjuvant therapy by the system[1].Camille(2010) develop medical management system for between 6 to 16 years old,it provide decision support for the healthy growth of children and youth in community[2]. In recent years, chinese scholars has invested a lot of research in the field of community health care, (Haitao Hou,2013) has developed the network monitoring system in real-time about community health care[1], that it provides real-time monitoring for seriously ill in community, and the system can provides real-time condition information reporting to doctor, so the time is winning to Treatment for acute illness. Meng Lin and Wan Zhong Chen(2013) has developed the community health management system that is based on ZigBee technology, which can real-time transfer patient's blood pressure, temperature and other data, in order to take appropriate measures timely, doctors can monitor the patient's relevant information[3]. Currentlly, the mainly service object of community medical management system is doctor and the intelligent of system is not enough, the research of health management model which aim at community residents and community decision-makers are still at early stages, in response, the paper proposes a model of community health care decision support, each community will have a community population health records and the record is updated at interval time. The appropriate health improvement suggestions can be given by medical experts through analyze a particular community, the objects of recommendations include individuals and community. If a community adopts expert advice, the personal physical health has been a big improvement and the proportion of the health population have raised greatly to whole community, the health statistics and the proposal are considered a success case and it will be promoted. 


\section{The establishment of community health examination database}

The residents of community is divided into different age groups, such as between 15 to 80 years old. Usually, there have much index of healthy, the paper select several indicators as a example, such as hyperlipidemia. Everyone has their own system account in community, the resident of community can enter system to view their own medical data. Over time, the resident can modify the value of physical indicators by login system, so the physical data are regularly updated and rebuild goal case-library by computing, the new medical advice can be obtained by case retrieval. The community decision makers can retrieve the most similar case from goal case-library by see the statistics data of community medical, in this way, the medical advice can be obtained from the most similar case for community population and provide the decision support to community decision maker. The statistics of community health examination data as shown in table 1:

Table $1 \times \times$ statistics of community health examination data

\begin{tabular}{|c|c|c|c|c|c|c|}
\hline $\begin{array}{l}\text { Age } \\
\text { Range }\end{array}$ & $\begin{array}{l}\text { Statistical } \\
\text { time }\end{array}$ & $\begin{array}{l}\text { The ratio } \\
\text { of healthy }\end{array}$ & $\begin{array}{l}\text { The ratio of } \\
\text { Hypertensive }\end{array}$ & $\begin{array}{l}\text { The ratio of } \\
\text { hypopiesia }\end{array}$ & $\begin{array}{l}\text { The ratio of } \\
\text { hyperglycemia }\end{array}$ & $\ldots \ldots$ \\
\hline $15-29$ & $\begin{array}{l}\times \text { year } \times \\
\text { mouth }\end{array}$ & $80 \%$ & $3 \%$ & $2.8 \%$ & $3.2 \%$ & ...... \\
\hline $30-44$ & $\begin{array}{l}\times \text { year } \times \\
\text { mouth }\end{array}$ & $68 \%$ & $12 \%$ & $2.6 \%$ & $8.2 \%$ & $\ldots \ldots$ \\
\hline $45-59$ & $\begin{array}{l}\times \text { year } \times \\
\text { mouth }\end{array}$ & $78 \%$ & $46 \%$ & $6 \%$ & $2.2 \%$ & $\ldots \ldots$ \\
\hline $60-80$ & $\begin{array}{l}\times \text { year } \times \\
\text { mouth }\end{array}$ & $55 \%$ & $60 \%$ & $35 \%$ & $22.5 \%$ & ...... \\
\hline
\end{tabular}

Table 1 shows the statistical results of the community residents health data, the community decision-makers landing system by their account and can see the statistical results of community health data. The paper mainly focus on community residents that medical data are sub-health status. The object of study involved and the process is shown in Fig.1:

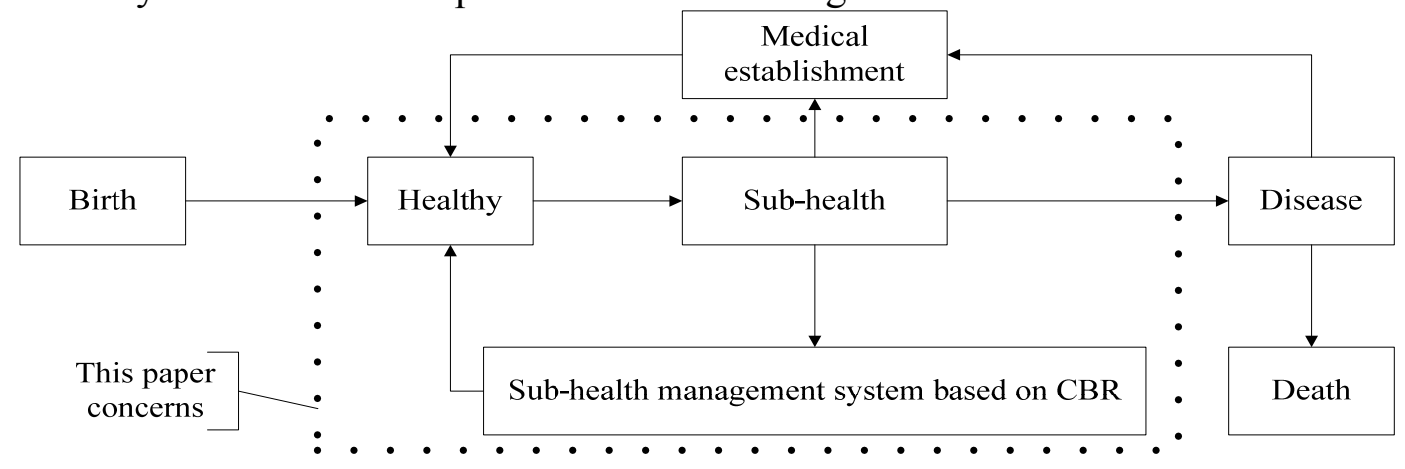

Fig. 1 object and process that is studied in this paper

The establishment of case base is the key of CBR, in this paper, we mainly discuss the establishment of community health statistics case-base. The case base contains not only the basic field data but also corresponding medical proposals, the medical proposals are given to counter community examination statistic data by experts in related fields. The paper discuss the case base that is different from the traditional CBR system, the swamp problem is existence in traditional CBR system, with the increase of cases in the case base, the retrieval time become longer and longer for CBR system, so the system lose efficiency, the case base contains two parts in this paper, the first is the target case base, which corresponding to the solution is very effective and repeating screen from foundation case base. The cases are sorted by the solution that in accordance with the effectiveness, the top 15 cases are selected as the target cases, which are storaged in target case base. The target case base always contains only 15 cases for an indicator of the community examination, so the swamp problem not happen to CBR system. The paper discusses the design and build process of target case base in next section. 


\section{The establishment of the target case base}

Study subjects were divided into $\mathrm{n}$ age groups, the number of physical tests is $\mathrm{m}$ for a community, the top 15 cases that are sorted in accordance with the effective, which are selected for examination of items in each age group, the total number of cases is $T(T=n * m * 15)$ in target case base. The ' $\mathrm{H}$ ' is defined as health index, which is basis to judge the case effect, It define as follow:

Definition 1 : If the community is divided into $\mathrm{n}$ age groups, the weight is $\operatorname{Gi}(\mathrm{i} \in[1, \mathrm{n}])$, which is provided for each segment, the number of each age groups is $\operatorname{Mi}(\mathrm{i} \in[1, \mathrm{n}])$, then the formula is defined as follow:

$$
G_{i}=\frac{M_{i}}{\sum_{i=1}^{n} M_{i}}(i \in[1, n])
$$

Definition 2 : If the community is divided into $\mathrm{n}$ age groups, the number of each age groups is $\mathrm{M}_{\mathrm{i}}(\mathrm{i} \in[1, \mathrm{n}])$, the items number of community health examination is $\mathrm{y}$, suppos the $\mathrm{K}_{\mathrm{j}}(\mathrm{j} \in[1, \mathrm{y}], \mathrm{K} \in[1, \mathrm{n}])$ is the number of community residents that physical examination project value is normal for the $K$ age groups and the first $j$ examination project, suppose the $g_{i j}(j \in[1, y], i \in[1, n])$ is the proportion of healthy persons for the $\mathrm{i}$ age groups and the first $\mathrm{j}$ examination project, then $\mathrm{g}_{\mathrm{ij}}=\mathrm{K}_{\mathrm{j}} / \mathrm{M}_{\mathrm{i}}(\mathrm{j} \in[1, \mathrm{y}], \mathrm{i} \in[1, \mathrm{n}])$ 。

Definition 3 : If the community is divided into $\mathrm{n}$ age groups, according to definitions 1 and 2, there is a suppose that the $\mathrm{H}_{\mathrm{x}}$ is health index of community in $\mathrm{x}$ year, then the formula is defined as follow:

$$
H_{x}=\frac{\sum_{i=1}^{n}\left(g_{i} \times G_{i}\right)}{n}(\mathrm{i} \in[1, \mathrm{n}])
$$

According to definition 3 , the health index value of a community can be obtained by caculating in a year, which subtract the health index value of last year, then, the ranking index that it is $\mathrm{r}(\mathrm{r}=\mathrm{Hx}-\mathrm{Hx}-1)$ can be acquired. According to the ranking index, the top target cases rank can be obtained by computing and storeged in target case base, so the case retrieval will retrieve the most similar case with the new cases in the target case base. The target cases are updated regularly in target case base, and the update period is one year, the update need to calculate the health index again counter the foundation case base and target case base, then ranking again, the top case is as target case, which is storeged in target case base. So the target case will change regularly, but the total of cases not change in target case base, the efficiency of case retrieval is not reduced.

\section{case retrieval}

The case retrieval is divided into two retrieval, the first is similarity search of community health Index, the second is similarity search about an health indicator and certain ages. The similarity retrieval formula about community health index is as follows:

$$
R=\sqrt{\sum_{i=1, j=1}^{n}\left(G_{i} * g_{i}-G_{j} * g_{j}\right)^{2}}(i \in[1, n], j \in[1, n])
$$

$\mathrm{R}$ represents similarity value of health index for two community, Gi represents weight of the $\mathrm{i}$ age groups, $\mathrm{Gj}$ represents weight of the $\mathrm{j}$ age groups, gi indicates the healthy proportion of the $\mathrm{i}$ physical indicators and gj indicates a healthy proportion of the $\mathrm{j}$ physical indicators, the value of $\mathrm{R}$ is smaller, indicating that the more similar the two communities.

The similarity search of physical tests formula for a certain age groups in their communities is as follows:

$$
R^{\prime}=\sqrt{\left(G_{i} * g_{i}-G_{j} * g_{j}\right)^{2}}(i, j \in[1, n])
$$

In formula (4), R'represents similarity value of physical tests for a certain age groups in their communities, the value of $\mathrm{R}^{\prime}$ is smaller, indicating that the more similar the two indicators. 
The most similar case is obtained by multiple compare with entire community health index, however, there are instances that many search result are the same similarity of health index, but the single index value is different in case retrieval, therefore, the retrieval of individual indicators have significance and their solutions have more valuable.

\section{The experimental simulation}

Taking the community hyperlipidemia population as an example, according to the medical statistics of community population health about health bureau. The five communities healthy statistics data are selected to simulate experimentation, the four age groups and related data is as follows:

Table 2 the proportion of the healthy population about hyperlipidemia medical projects

\begin{tabular}{ccccccc}
\hline Age Range & Year & \multirow{2}{*}{ Community 1 } & $\begin{array}{c}\text { Proposal of } \\
\text { Community 1 }\end{array}$ & $\begin{array}{c}\text { Community } \\
2\end{array}$ & $\begin{array}{c}\text { Proposal of } \\
\text { Community 2 }\end{array}$ & $\ldots \ldots$ \\
\hline $15-29$ & 2010 & 0.958 & Decision scheme & 0.921 & Decision scheme & $\ldots \ldots$ \\
$15-29$ & 2011 & 0.968 & Decision scheme & 0.915 & Decision scheme & $\ldots \ldots$ \\
$30-44$ & 2010 & 0.685 & Decision scheme & 0.765 & Decision scheme & $\ldots \ldots$ \\
$30-44$ & 2011 & 0.758 & Decision scheme & 0.755 & Decision scheme & $\ldots \ldots$ \\
$45-59$ & 2010 & 0.553 & Decision scheme & 0.658 & Decision scheme & $\ldots \ldots$ \\
$45-59$ & 2011 & 0.689 & Decision scheme & 0.532 & Decision scheme & $\ldots \ldots$ \\
$60-80$ & 2010 & 0.336 & Decision scheme & 0.258 & Decision scheme & $\ldots \ldots$ \\
$60-80$ & 2011 & 0.345 & Decision scheme & 0.229 & Decision scheme & $\ldots \ldots$ \\
\hline
\end{tabular}

We can draw a conclusion from table 2, the outcomes of health improvement are different, mostly because of the different health improvement program that community policymakers adopt. After the reasonable health improvement program is adopted by policymakers, the total population proportion of community health have improved markedly. The five community are selected to calculate the health index, then, the top front of the three communities are selected as target case that are storeged in case base, the simulation results as shown below:

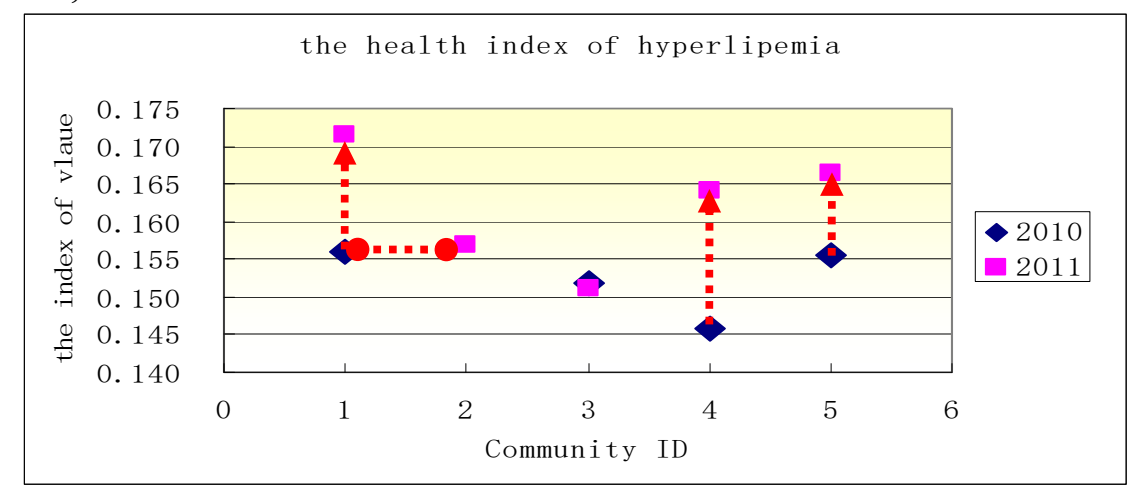

Fig. 2 the health index of hyperlipemia

The health index is the highest for community_1 in 2010 that it can be seen from figure, the health index of community_4 is the lowest in 2010, however,after community decision-makers take decision measures, the health index of community_ 4 growth is the largest until 2011, the growth of commuinty_3 is the slowest.Community_1 and community_2 is the most similar for comparative case similarity in 2010 year, therefore, the improvement scheme of community_1 is adopted for community_2. There may be cases where more than one community similarity equal from the case similarity comparisons, but the similarity are different for communities age groups, it is as follow shown: 


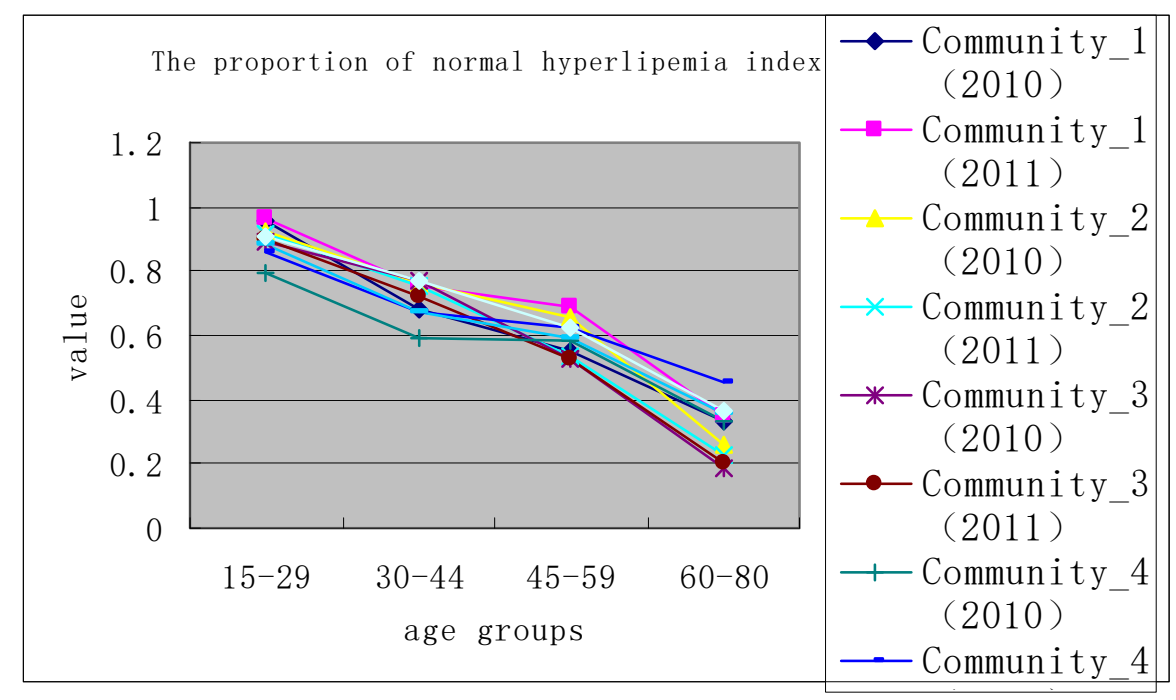

Fig. 3 the proportion of normal hyperlipemia index

According to the condition, the paper propose similarity search in two steps, the first step is to retrieve the most similar case with the new case from the target case base, the new case can retrieve the most similar case from target case base based on the different age groups, it is as follow shown:

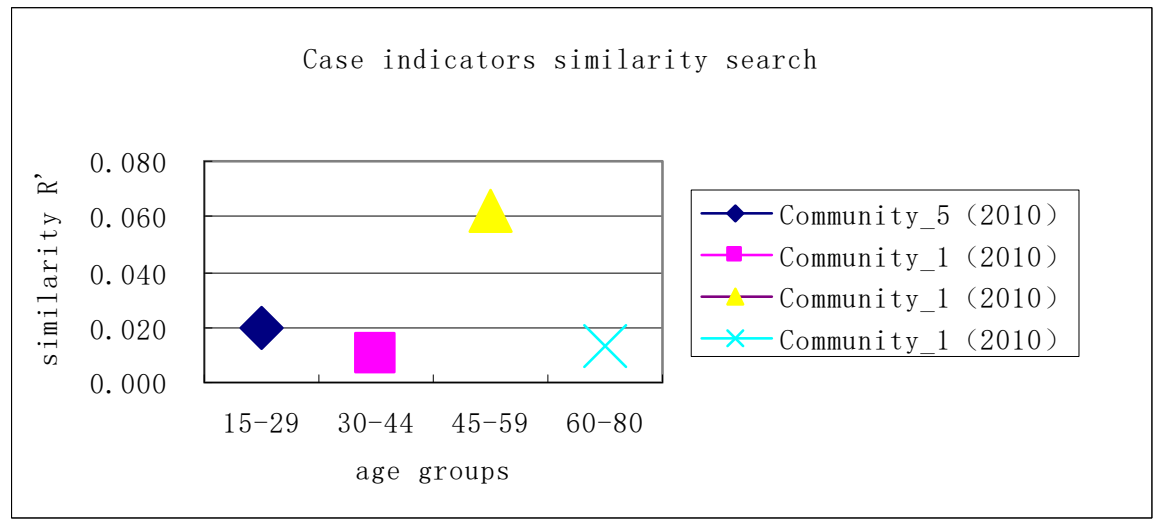

Fig. 4 the similarity search of age groups

As can be seen from Fig.4 , overall, community_1 and community_2 is the most similar, according to age groups retrieval, the community_1 have three age groups are very similar with community_2,community_5 have one age groups are very similar with community_2.

The age groups health improvement program are storeged in target case base, which have great reuse and reference value, experiments show that the model results comform to the actual basically.

\section{Conclusions}

The paper discusses the decision support model for community health care based on a CBR, the case-based reasoning technology is used to promote successful community decision scheme, in order to effectively solve the problem of CBR systems swamp, the paper designing a new target case base, Finally, the five community and nearly two years statistical data of hyperlipemia examination are applied to simulation, experiment results show that the model accuracy conform to actual basically, the model has a larger value. However, the model also has some disadvantages, such as the field of retrieval characteristic is single and has not take into account the severity of disease, to a degree, the final result of case reuse is affected, all these problems need to be researched further.

\section{Acknowledgements}

This work were supported by double stand plan from sichuan agricultural university. 


\section{References}

[1] H.T. Hou. Health real-time monitoring network system for community health(Ph.D.,Xidian University, china 2012).

[2] Kunlun Li, Lu Jun.The application of technology that is the Internet of things for family and community health care, Microcontroller \& Embedded System Application,(2011)No.6, 63-65. (In Chinese)

[3]Chen chen Gu,Li Jian,Zhaoke Hu.The paper is the research on health information exchange programs, Digital Technology and Application, (2012)No.12. (In Chinese)

[4]Jiahu Tao. The research of standardized management about community's healthy examination, China community doctors, Vol.21(2012)No.14,p.342-343. (In Chinese)

[5] Lu Jia. The effect and significance that health education are imported in healthy examination for community residents, Zhejiang clinical medicine, Vol.15(2013)No.5,p.739-740. (In Chinese)

[6]Tangmin Hu, Yanling He. Research on Knowledge Management Based on case based reasoning, Journal of information, (2009)No.2,p.129-136. (In Chinese)

[7]Yuan Guo, Jie Hu,Yinghong Peng. A CBR system for injection mould design based on ontology: A case study. Computer-Aided Design,(2012)No.44,p.496-508.

[8] Shen Tsu Wang, WenTsann Lin. Research on integrating different methods of neural networks with case-based reasoning and rule-based system to infer causes of notebook computer breakdown, Expert Systems with Applications ,(2010)No.37,p.4544-4555. 